\title{
RELIGIOSIDADE CATÓLICA E AS SUAS INFLUÊNCIAS NA COLÔNIA GERMÂNICA SANTA CLARA (1911-1917)
}

\author{
Simone Elisa Weber ${ }^{1}$
}

\begin{abstract}
Resumo: Este artigo tem como objetivo principal compreender as movimentaçóes sociais e financeiras ocorridas na Vila Santa Clara/RS entre os anos de 1911 e 1917, relacionadas à construçáo da Igreja Matriz Sáo Francisco Xavier. O trabalho é resultado de uma pesquisa realizada junto ao acervo da paróquia e da análise de registros constantes no livro caixa da comunidade, durante o período estudado. Pode-se observar o aumento da movimentação e do envolvimento social e financeiro da comunidade em geral, visto que esta se caracterizava no período como uma pequena vila de descendentes de imigrantes germânicos, em especial de praticantes do catolicismo, que ainda mantinham diversos traços sociais e organizacionais de seus antepassados.
\end{abstract}

Palavras-chave: Teuto-brasileiros. Catolicismo. Comunidade.

\begin{abstract}
This article aims to understand the social and financial transactions that took place in Vila Santa Clara / RS between the years 1911 and 1917, related to the construction of the São Francisco Xavier Church. It is the result of the study of the parish records of that period. It was noticed increased movements and increased socio-financial involvement of the community in general, as this was characterized at the time as a small village of descendants of German immigrants, particularly Catholicism practitioners, who still held many social and organizational traits from their ancestors.
\end{abstract}

Keywords: German-Brazilians. Catholicism. Community.

\section{INTRODUÇÃO}

O atual município de Santa Clara do Sul localiza-se na região central do Rio Grande do Sul, fazendo parte do chamado Vale do Taquari. Possui fortes influências da colonização germânica iniciada em seu território em 1869. Estes imigrantes/ migrantes levaram consigo traços culturais e sociais, tais como a língua, alimentação e religiosidade. Ainda hoje, a comunidade em questão é de maioria católica, sendo um elemento vinculado ao período de colonização da então Fazenda Santa Clara.

1 Graduanda do curso de Licenciatura em História do Centro Universitário UNIVATES. E-mail: mone-weber@hotmail.com. 
Adquirida por Fialho de Vargas em meados do século XIX, a Fazenda Santa Clara é loteada e os lotes de terra são revendidos aos imigrantes e migrantes de ascendência germânica, muitos destes advindos das chamadas colônias Velhas, nos Vales dos rios Sinos e Caí. Estes colonizadores, conforme Träsel (1969), são de maioria católica, e desde os primeiros anos, passam a organizar-se comunitariamente em torno de uma capela-escola e um cemitério, localizados no centro da colônia.

Ainda no século XIX são construídas duas capelas-escola (uma substituindo a outra), conforme a necessidade apresentada com o crescimento populacional. No princípio da década de 1910, a comunidade decide pela construção de um novo templo, porém desta vez, seria uma igreja, com tamanho e estrutura que pudessem suprir as necessidades comunitárias por várias décadas.

A Igreja Matriz São Francisco Xavier é construída entre os anos de 1913 e 1916 pela Comunidade Católica da Vila Santa Clara - região central da antiga Fazenda. É importante observar que a Paróquia São Francisco Xavier é criada oficialmente apenas em 1930, sendo assim, neste período a comunidade é atendida pelos padres advindos de Lajeado, da Paróquia Santo Inácio de Loyola.

Junto ao acervo documental da Paróquia São Francisco Xavier, encontra-se um livro caixa, utilizado entre os anos de 1910 e 1924, abarcando assim, o período de construção do templo. Este documento apresenta os dados contábeis da comunidade no período, com descrições minuciosas das doações e contribuições das famílias. A partir deste documento buscar-se-á compreender as movimentações sociais e financeiras ocorridas na Vila Santa Clara/RS entre os anos de 1911 e 1917, relacionadas à construção da Igreja Matriz São Francisco Xavier, sendo importante o mapeamento realizado das famílias contribuintes e análise da maneira com a qual estes dados foram registrados.

Uma das dificuldades encontradas para que a análise pudesse ser concretizada é a de que os registros, em sua grande maioria, encontram-se em alemão e na grafia gótica. Assim, foi possível a verificação somente a partir dos nomes, que em sua maioria puderam ser compreendidos. Dentre as verificações realizadas estão o aumento significativo das contribuições (tanto em valores, quanto em quantidade de doações por ano e até de contribuintes), que coincidem com o início das obras de construção. Pode-se analisar, ainda, a maneira com a qual são representadas as mulheres nestes registros.

\section{COLONIZAÇÃO GERMÂNICA NO RIO GRANDE DO SUL E NO VALE DO TAQUARI NO SÉCULO XIX}

Os primeiros imigrantes germânicos chegam ao Rio Grande do Sul em 25 de julho de 1824, sendo inicialmente assentados junto à chamada Feitoria do Linho Cânhamo (atual município de São Leopoldo). É deste ponto geográfico que inicia a colonização germânica no Rio Grande do Sul, que durante todo o século XIX foi espalhando-se pela província em diversas colônias, linhas e picadas. Conforme o avançar do século, a maneira de atração, a quantidade de imigrantes e as condições 
que lhes eram oferecidas, foram sendo modificadas por diferentes questões econômicas, políticas e legislativas.

Com o aumento populacional das primeiras colônias, a vinda de mais imigrantes e o esgotamento do solo dos primeiros lotes adquiridos, imigrantes e seus descendentes passam a migrar em direção às novas colônias no interior da Província, em um processo denominado por Roche (1969) como enxamagem. Estas novas colônias surgem, principalmente, através de iniciativas privadas, tais como as colônias de Teutônia, Estrela e Lajeado.

As primeiras colônias no Vale do Taquari, segundo Roche (1969), passam a ser ocupadas por imigrantes e seus descendentes no início da década de 1850, através de empresas privadas, que loteavam as fazendas já existentes e vendiam pequenas porções de terras. Conforme Ahlert e Gedoz (2001)

[...] estabeleceu-se na região um expressivo setor de negócios imobiliários privados, mediante a transferência de terras dos antigos proprietários para empreendedores, que organizavam o loteamento e a venda das terras para os colonos, sob a supervisão dos governos provinciais (p. 50).

A partir dos territórios que margeiam o Rio Taquari inicia-se a ocupação e abertura de picadas e linhas, que se tornariam pequenas vilas e núcleos urbanizados. A té a década de $1870^{2}$ a grande maioria destas localidades recebeu majoritariamente imigrantes e descendentes de germânicos, formando pequenos núcleos coloniais.

A região do atual município de Lajeado e de outros municípios cujos territórios foram desmembrados do primeiro, pertenceu em grande parte à Antônio Fialho de Vargas e a sua Companhia, denominada Batista \& Fialho Cia. Fialho de Vargas possuía metade das ações de dita empresa, fixou residência na então Colônia dos Conventos (atual bairro Carneiros em Lajeado) e foi o responsável pela organização e administração da empresa colonizadora. Conforme Schierholt (1992), a residência de Fialho de Vargas e um pequeno núcleo urbano foram instalados junto a um grande paredão localizado às margens do Rio Taquari, na Fazenda de sua propriedade. De maneira poética o autor elucida que: "do "paredão" se avista longe o Rio Taquari e ali se plantou a semente que ramificou dezenas de linhas coloniais e povoação, hoje prósperas cidades e distritos de Lajeado” (p. 63).

Após iniciar a venda de lotes de terras das Fazendas (então transformadas em colônias) Conventos e São José dos Conventos, Fialho inicia a compra de outras grandes áreas de terras, localizadas mais distantes do Rio Taquari, objetivando também dividi-las em lotes coloniais para futuras vendas. Dentre estas Schierholt (1992) cita as Fazendas Forqueta, São Bento e São Caetano, atualmente situadas respectivamente nos municípios de Arroio do Meio, Lajeado/Santa Clara do Sul e Cruzeiro do Sul, além de áreas localizadas em Estrela e Muçum.

Antônio Fialho de Vargas torna a compra e venda de terras para imigrantes e descendentes um negócio lucrativo. Sendo isso facilitado pela lei de terras de

2 Quando inicia a colonização italiana na região. 
1850, que favorecia e dava prioridade à compra de terras devolutas àqueles que já possuíam maiores propriedades. O empresário, além de realizar a venda de lotes, também buscava incentivar a vinda de imigrantes germânicos através de diversas estratégias.

Esse negociante, com a finalidade de atrair colonos estrangeiros, firmava
contratos provisórios na Alemanha, os quais eram transformados em
contratos oficiais com a chegada dos imigrantes ao Brasil. O empresário
financiava o comprador, tanto na compra das terras, como na de sementes
e na alimentação até a primeira colheita, além de conceder adiantamentos,
segundo o número de pessoas da família (AHLERT; GEDOZ, 2001, p. 69).

Percebe-se, a partir da análise de Schierholt, a importância da imigração e migração de germânicos e teuto-brasileiros nestes primeiros anos de colonização no Vale do Taquari. Esse processo permitiu tanto a movimentação econômica, quanto a ocupação de ditas terras devolutas, que segundo o mesmo autor, anteriormente, haviam sido ocupadas por grandes latifundiários, mas que acabaram sendo abandonadas pelos mesmos ainda no início do século XIX por diversos motivos.

Muitos destes primeiros compradores de terras nas colônias pertencentes à Antônio Fialho de Vargas, mesmo sendo de origem germânica, advinham de outras colônias gaúchas, como Dois Irmãos e São Leopoldo. Configura-se, portanto, um movimento de atração de imigrantes vindos do outro lado do Atlântico, bem como daqueles que já haviam se estabelecido em outras regiões do estado.

\section{COLONIZAÇÃO E CONSTITUIÇÁO DA VILA SANTA CLARA (1869 A 1900)}

A Fazenda Santa Clara foi mais uma das áreas de terra adquiridas por Antônio Fialho de Vargas e sua Companhia, no Vale do Taquari. O empresário tinha como característica adquirir grandes áreas de terra para após loteá-las e revendê-las para a formação da pequena propriedade familiar, em especial aos imigrantes europeus e seus descendentes (SCHIERHOLT, 1992).

Os primeiros colonos chegam à Fazenda Santa Clara entre os anos de 1869 e 1874, todos advindos das primeiras colônias (também chamadas de colônias velhas) localizadas nos Vales dos rios Sinos e Caí, e de origem germânica (alemã e austríaca). Seriam eles: Antônio Kunz e Ana Sofia Mallmann, “[...] André Köhnlein, vindo de São Leopoldo; viúva Scheibler com filhos adultos, oriundos de Gablonz (Boêmia, Áustria); Felipe Schäfer, natural da Alemanha; Jacó Kaiser, da Alemanha; Carlos Pietschmann, Jacó Lenhard e Martim Reis, também da Alemanha" (TRÄSEL, 1969, p.13).

A organização inicial e os primeiros anos de adaptação foram de muitas dificuldades. A Fazenda era distante e isolada de centros um pouco mais organizados e que possuíam estabelecimentos comerciais, tais como Lajeado e Cruzeiro do Sul. As propriedades adquiridas, em grande parte, ainda possuíam a vegetação nativa, o que dificultava o desenvolvimento e o cultivo da alimentação necessária para as numerosas famílias. 
Conforme Träsel (1969), a população, de maioria católica, carecia de atendimento religioso e espiritual que lhes auxiliasse em todas as dificuldades enfrentadas nas novas propriedades. Muitos se deslocavam, aos domingos, até Estrela ${ }^{3}$, onde havia a Paróquia mais próxima, ou em algumas ocasiões foram realizadas celebrações na casa de Guilherme Werlang. Outra carência da comunidade era a falta de uma escola para as crianças, a instituição mais próxima localizava-se em Cruzeiro do Sul, sendo assim, a distância impedia o deslocamento diário.

André Köhlein, o primeiro colono a instalar-se na Fazenda, havia adquirido diversas porções de terra de Fialho de Vargas. Quando surge a necessidade e a possibilidade de construção da primeira capela-escola, já tendo reservado um pequeno terreno para o cemitério ${ }^{4}$, doa uma área de terras à comunidade católica. A construção do primeiro templo é realizada a partir de 1880.

Edificaram a linda capela-escola, deixando-a completamente pronta no dia 3 de dezembro de 1881, data de sua inauguração. Os fundamentos da capela foram de pedra, as paredes de enxaimel e a tôre de madeira, ao passo que a escadaria foi de troncos falquejados de madeira de lei (TRASEL, 1969, p. 17).

Em 1885 a comunidade contava com cerca de 87 famílias, e até 1890 seriam mais 78 , o que resultaria em um crescimento populacional considerável, levandose em conta as poucas décadas de ocupação. A primeira capela-escola torna-se pequena, sendo necessária a construção de outro templo, que pudesse suportar a quantidade de fiéis que participavam das celebrações religiosas, mas também que tivesse espaço para todas as crianças que frequentavam as aulas. Assim, entre 1893 e 1896 é edificada a segunda capela-escola da comunidade, justamente ao lado da primeira edificação. No Álbum Jubilar, de autoria do Pe. Alberto Träsel, pode-se encontrar um registro fotográfico das referidas construções.

Estas duas primeiras capelas-escolas atendiam as localidades de "[...] a sede Santa Clara (Santa Clara Baixa), Schuster - Mählereck (Santa Clara Alta), Sampainho, Nova Santa Cruz, São Bento (parte superior), Augusta, São Rafael, Aurora e o Vale de Sampaio (lado esquerdo)" (TRÄSEL, 1969, p.17). O responsável pelas aulas era o professor Pitter Hannes Mallmann, imigrante alemão, que antes de chegar à Santa Clara já havia lecionado em outras duas comunidades em Dois Irmãos. O professor atuou na comunidade entre os anos de 1882 e 1898.

Para Lando e Barros (1976) a educação e a organização escolar desenvolvidas nas colônias alemãs resultou no isolamento social e cultural destes imigrantes alemães até as primeiras décadas do século XX. Para os mesmos autores, o governo pouco se interessava pela educação nos núcleos coloniais, visto que as escolas

3 Distante aproximadamente $25 \mathrm{~km}$.

4 Köhlein havia reservado o referido terreno para o cemitério, pois em meados da década de 1870 falece uma de suas filhas, sendo esta ali sepultada. Em 1877, falece ainda bebê o filho de Guilherme Werlang, que é sepultado junto à filha de Köhnlein, originando-se assim o primeiro cemitério da comunidade. 
provinciais eram insuficientes e muitas vezes, os professores destas escolas eram os próprios imigrantes, bem como multiplicavam-se as escolas de iniciativa particular, mantidas pelos pais dos alunos, sendo na maioria das vezes de caráter confessional. Como se pode perceber no caso santa-clarense, tanto a iniciativa para a construção de um espaço escolar, quanto o mantimento do mesmo e do professor, foram de responsabilidade dos colonos, bem como tiveram fortes ligações com a religiosidade católica. Tal fato resultou na manutenção do dialeto alemão, tanto na fala, quanto na leitura e escrita, o que passou a modificar-se gradativamente apenas na década de 1930.

Durante estas primeiras décadas de existência da colônia, em diversos momentos, foi necessária a organização e união da comunidade. Como exemplos podemos citar a construção das capelas-escola já mencionadas, bem como na construção das moradias, no trabalho para a limpeza e preparação do terreno (possibilitando o plantio e a colheita) e na abertura de estradas.

Um destes momentos, que ficou marcado profundamente na história da colônia foi a invasão de combatentes Maragatos ${ }^{5}$ à Vila Santa Clara, ocorrido no dia 28 de maio de 1895. Conforme Schorr (2007), o grupo que invadiu a Vila era composto principalmente de antigos moradores do território, que ali já estavam estabelecidos antes da comercialização dos lotes pela Companhia de Fialho de Vargas e que são expulsos para as regiões mais altas quando chegam os novos colonizadores. Estes passam a comercializar erva-mate e madeira para as regiões baixas, com grandes dificuldades para o transporte de seus produtos por conta das longas distâncias a percorrer.

Com a ascensão de Júlio de Castilhos e a troca dos intendentes, começaram os negociantes republicanos a não comprar os produtos, por aquele grupo ser considerado "gente do outro lado", ocasionando uma grave crise econômica e, falta de alimento para a população. Surgia então a necessidade de saquear residências, casas comerciais para obter alimentos, bens que poderiam ser comercializados com facilidade (SCHORR, 2007, p. 33).

Assim, estes grupos passam a seguir integrantes do Partido Federalista, como Zeca Ferreira, no Vale do Taquari. Estes, para sustentar-se, passam a exigir recursos de algumas comunidades e/ou saqueá-las buscando alimentos e bens (como animais e joias). A Vila Santa Clara teria recebido diversas correspondências do grupo de Zeca Ferreira exigindo tais auxílios. Conforme Schorr (2007), em primeira instância os colonos teriam aceito os pedidos, enviando alimentos, cavalos e gado. Porém, após grande quantidade de cartas, anúncios e ameaças, os colonos decidem por não aceitar os pedidos e organizam-se para o inevitável confronto, criando táticas e buscando armamentos. A invasão ocorre na manhã de 28 de maio de 1895, resultando na fuga dos invasores. A união dos moradores representou a defesa dos

5 Grupo inserido na Revolução Federalista, que ocorria por toda a Província de Rio Grande de São Pedro. 
interesses da comunidade e resultou na criação da Sociedade Alemã de Atiradores de Santa Clara, entidade que se tornaria um importante espaço de sociabilidades.

Para além da sobrevivência e sociabilidade, foi a religiosidade um forte elemento de coesão comunitária. Conforme o Pe. Alberto Träsel, o século XIX finda em Santa Clara com um grande evento, o $2^{\circ}$ Congresso Geral dos Católicos do Rio Grande do Sul, ocorrido na Vila Santa Clara entre os dias 14 e 16 de abril de 1899. O autor realiza uma detalhada descrição de cada um dos três dias de evento, das impressões e resoluções. Este Congresso teria reunido cerca de 3.500 pessoas, advindas tanto de colônias próximas como Lajeado, Estrela, Santa Cruz e Venâncio Aires, quanto das mais distantes como Feliz, Harmonia, São Salvador ${ }^{6}$, Montenegro e Dois Irmãos. A organização da comunidade para receber tal evento foi grandiosa, com a construção de um grande pavilhão com energia elétrica e organização das famílias para acolher, hospedar e alimentar os visitantes e seus animais.

Com relação à forte religiosidade dos imigrantes germânicos e seus descendentes no Rio Grande do Sul, Jean Roche nos diz que "a religiosidade dos colonos parece mesmo ter aumentado, em virtude, sem dúvida, da coesão familiar e do controle exercido pela comunidade dentro do relativo isolamento de sua vida pioneira" (1969, p. 671). O historiador Ryan de Sousa Oliveira (2008), em sua dissertação, enfatiza a importância da religiosidade nas comunidades alemãs de confissão luterana e nas comunidades católicas no contexto das colônias, em especial às diferentes maneiras associativas que foram criadas por estes indivíduos, como forma de representação e de coesão destes grupos. No caso da colônia Santa Clara, a igreja também apresentava-se era um importante meio de união e organização comunitária. Através da qual, eram organizados eventos assim como o ocorrido na localidade no ano de 1899, sendo mais um exemplo da organização dos católicos teuto-brasileiros dentro deste contexto.

\section{CONSTRUÇÃO DA IGREJA MATRIZ SÃO FRANCISCO XAVIER: MODIFICAÇÓES E INFLUÊNCIAS NA PEQUENA VILA DE SANTA CLARA (1911 - 1917)}

Conforme dados de Roche (1969), a população teuto-brasileira ${ }^{7}$ sofreu ligeiro aumento desde o início do período imigratório até 1950 (período por ele analisado). Assim ocorria na Colônia Santa Clara desde a sua fundação, acentuandose tal característica com o passar dos anos e a constituição e organização estável da comunidade.

Com a comunidade em franco crescimento, tanto em função dos nascimentos, quanto por novos migrantes que continuavam a chegar de outras colônias, a

6 Atualmente a cidade de Salvador do Sul.

7 O autor define como teuto-brasileiro aquele que tenha tanto pai, quanto mãe de origem germânica, descartando-se assim de sua análise todo aquele que possua apenas um de seus progenitores com tal origem. 
comunidade católica percebe a necessidade de construção de uma nova igreja, pois a segunda edificada ainda na última década já não suportava a quantidade de fiéis.

As movimentações efetivas passam a ocorrer em 1912 quando, conforme Träsel (1969), segue para a Vila Santa Clara o Pe. Pedro Gasper (Vigário de Lajeado) buscando organizar a forma de coleta para os subsídios necessários para a construção da nova Igreja. É interessante perceber que nem todos os habitantes da comunidade apoiavam tal decisão. Se tem como exemplo o caso dos moradores de Picada Augusta ${ }^{8}$ que haviam decidido separar-se da Capela localizada na Vila e edificar uma para atender às suas necessidades, o que dificultaria a construção da Igreja por conta da necessidade das doações de dita comunidade.

A última celebração realizada na antiga capela ocorre em 27 de abril de 1913. "Nesta data celebraram-se, pela derradeira vez, as funções sagradas na antiga (segunda) capela, que foi imediatamente demolida, para que, no mesmo ponto, se reedificasse uma nova igreja, correspondente ao número dos habitantes" (TRAESEL, 1969, p. 53).

Como já referenciado anteriormente, no acervo da Paróquia São Francisco Xavier encontra-se um livro caixa utilizado no período de construção da referida igreja. Este nos traz diversas possibilidades de análise, por seus minuciosos registros. Porém algumas dificuldades são encontradas. A principal delas é a de que grande parte do documento encontra-se escrito na grafia alemã gótica, dificultando a sua tradução ao português.

A manutenção dos dialetos germânicos nas colônias teuto-brasileiras é uma característica importante das mesmas. Conforme Roche (1969) o isolamento de ditas colônias, acentuado por questões educacionais e pelos casamentos que ocorriam em grande maioria entre teuto-brasileiros, resultou também na preservação dos dialetos de origem germânica.

Quando se fundaram as primeiras colônias na borda da Serra, seu isolamento condenava os imigrantes a conservar o uso de sua própria língua. Sem contatos com os elementos luso-brasileiros, não tinham nem necessidade nem ocasião de aprender o português, que recuava mesmo à medida que se estendia a zona de colonização (ROCHE, 1969, p. 654).

Situação semelhante ocorre em Santa Clara, onde se sabe que a maioria de seus habitantes, mesmo os de terceira geração no Brasil, apenas comunicavam-se por dialetos alemães, no período estudado. Observa-se que os professores eram de origem germânica, sendo assim, suas aulas eram ministradas somente em alemão, desenvolvendo e mantendo assim somente a fala, a leitura e a escrita em dito idioma.

No livro objeto de análise neste estudo é interessante observar tais características, que aparecem de diferentes maneiras, na grafia utilizada, na maneira

8 Picada Augusta é uma pequena comunidade, localizada no município de Cruzeiro do Sul, fazendo divisa com Santa Clara do Sul. É interessante observar porém, que a mesma ainda é associada à Paróquia São Francisco Xavier. 
com a qual são escritos os nomes das pessoas, mas também na mescla que pode ser observada entre as duas grafias. Em um mesmo registro pode-se observar, por exemplo, o nome do doador registrado de maneira legível ${ }^{9}$ e as informações adicionais em escrita gótica. Sendo assim, é possível criar-se a hipótese de que ocorre uma separação, mesmo que não proposital, das grafias de palavras que já faziam parte do contexto brasileiro (como os nomes, que claramente já haviam sofrido tal influência), com aquelas que eram de influência familiar.

[...] A adoção de numerosos têrmos brasileiros, de parentesco e de amizade, revela nova função da vida social. Os canais dessa infiltração têm os contatos com os caboclos, as relações administrativas e políticas, as atividades profissionais. Em compensação, quase não há nenhum termo eclesiástico português no falar teuto-brasileiro: seria a prova de que a vida religiosa ficou isolada do meio brasileiro (ROCHE, 1969, p. 658).

Nos dados analisados a partir da fonte documental descrita, pode-se perceber estas e outras características da colônia de Santa Clara, ainda que os mesmos datam de quase meio século após a chegada dos primeiros colonos. Visto que se tem como objetivo observar os dados referentes ao período da construção da Igreja Matriz, delimitou-se a análise dos dados contidos no livro-caixa que datam entre os anos de 1911 e 1917. Para tal, buscou-se realizar uma análise quantitativa com análise de conteúdo. É importante ainda ressaltar que a moeda corrente no Brasil no período estudado era o Réis. Logo, os valores representados nos gráficos, bem como contidos nos registros paroquiais representam esta moed $a^{10}$.

Pode-se constatar que a construção da Igreja movimentou significativamente a comunidade, já que foi necessário o esforço de muitas pessoas para que a grandiosa obra pudesse ser realizada. Como se pode observar no Gráfico I, após o início das construções, em 1913, ocorre um grande aumento nas contribuições anuais dos associados à Comunidade Católica, ocorrendo o auge das mesmas no ano de 1916, marcado pelo fim da edificação e pela inauguração do templo. Já no ano seguinte, pode-se observar uma importante queda dos valores doados. É possível assim, concluir-se que os montantes doados no período estavam intimamente ligados ao objetivo de toda a comunidade, que era o de concluir a construção de seu novo templo.

9 Para esta observadora que não compreende a grafia gótica.

10 Para possibilitar a realização de uma comparação e compreender a relação dos valores do período com os atuais, será utilizada uma ferramenta criada pelo jornal O Estadão, através do qual é realizado o cálculo de equivalência utilizando como base o valor nos quais eram comercializados os jornais em cada período. Por exemplo, em 1913 cada jornal custava $\$ 100$ (cem réis). 
Gráfico 1 - Valores totais de arrecadação por ano

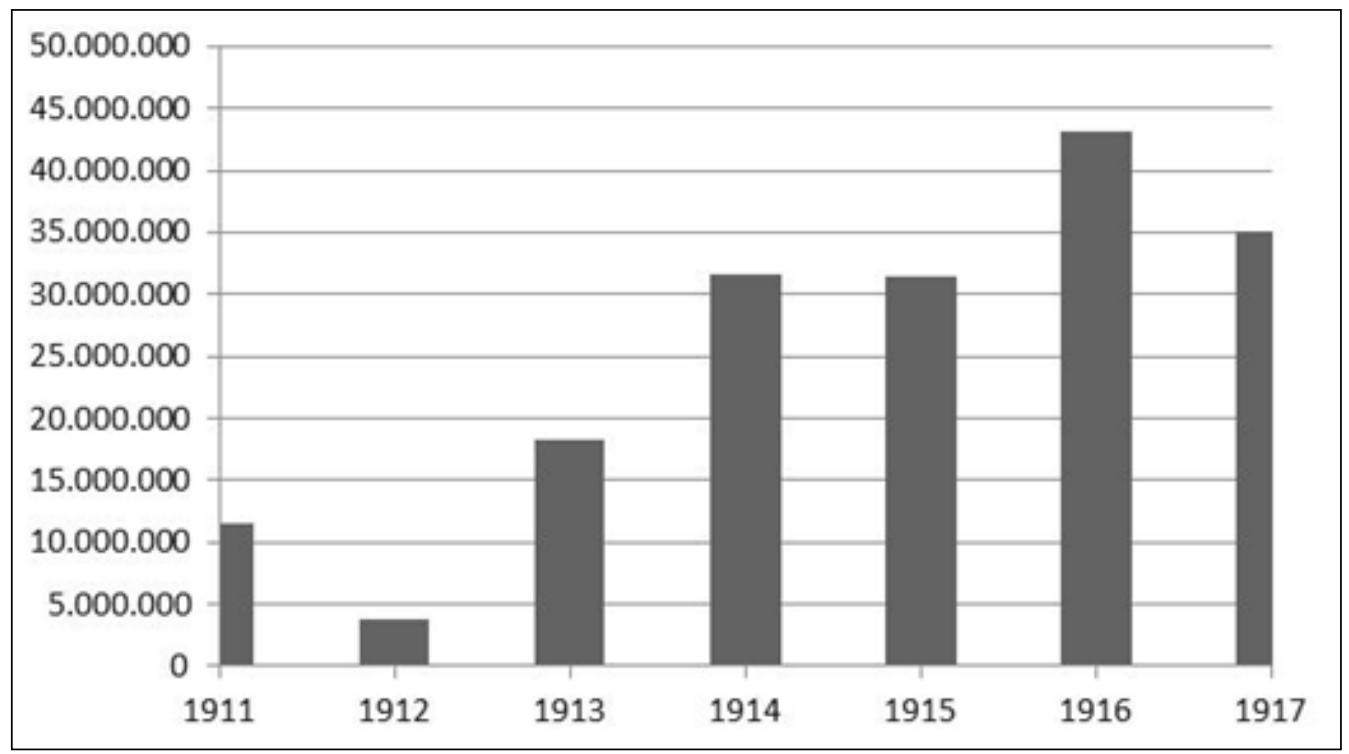

Fonte: Livro Caixa - Acervo Paróquia São Francisco Xavier (2015).

Um dos fatores que pode ter contribuído para o aumento das doações foi a modificação da regra existente em relação ao pagamento das contribuições das famílias por ano à comunidade católica. Conforme Träsel (1969), anteriormente, o valor da contribuição era espontâneo, já em 1912 (com a obra por iniciar) decidese que será estipulado um valor mínimo de contribuição anual por família, bem como se pode observar que algumas famílias ${ }^{11}$ pagam anualmente uma taxa de 5 ou $6 \%$ do total de seus bens. Tal modificação, portanto, fez com que houvesse a obrigatoriedade do pagamento, fazendo com que os valores doados subissem consideravelmente no ano de 1913, como pode ser observado no Gráfico 1.

No Gráfico 2, pode-se compreender ainda a grande variação entre os valores doados por cada associado. São aqui apresentados como exemplo os dados do ano de 1913 , quando a variação foi de $\$ 2.000,00$ à $\$ 2: 104.000,00$. A partir de tais dados, observa-se que na comunidade havia uma grande variação econômica entre os habitantes, já que alguns possuíam condições financeiras para realizar doações de montantes bastante significativos e outros, tinham a necessidade de parcelar o valor das contribuições mínimas anuais.

11 Não foi possível a compreensão dos critérios existentes para delimitar quais famílias contribuíam com tal porcentagem. 
Gráfico 2 - Variação de valores doados em 1913

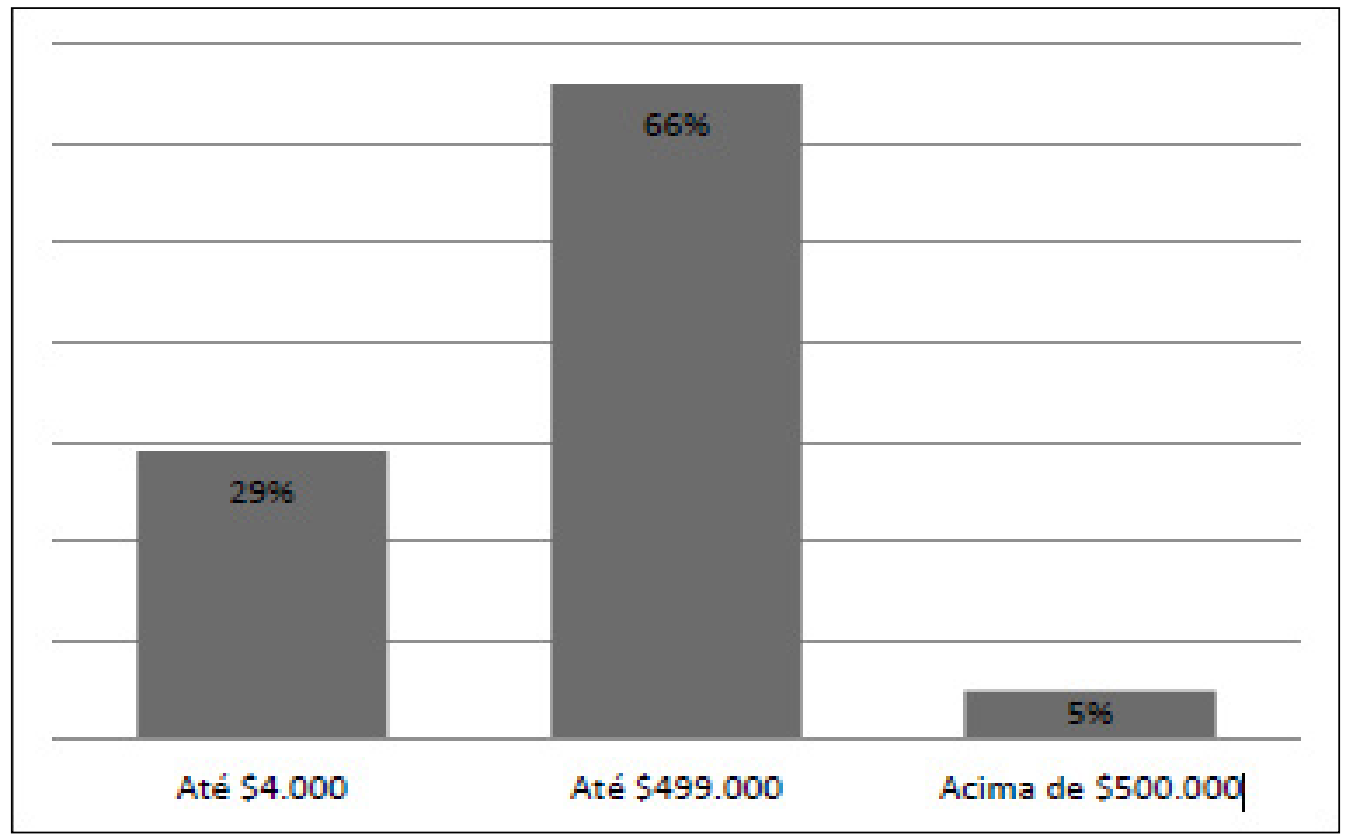

Fonte: Livro Caixa - Acervo Paróquia São Francisco Xavier (2015).

Percebe-se assim que no ano de $1913^{12} 29 \%$ dos associados realizaram doações no valor máximo de $\$ 4.000,00,66 \%$ foram os que doaram até $\$ 499.000$, 00 e 5\% foram doações acima de $\$ 500.000,00$. Observa-se assim, que a maioria das pessoas contribuía com valores bastante acima dos solicitados, demonstrando a importância que a construção da Igreja à São Francisco Xavier ganhou na comunidade de Santa Clara.

Já o ano de 1916 destaca-se pela maior quantidade de contribuições acima de $\$ 500.000,00$, sendo que isto pode ser em virtude dos esforços necessários para o término da construção do templo, inaugurado no dia $1^{\circ}$ de outubro de 1916 . Foram $13 \%$ de associados que realizaram doações de valores acima de $\$ 500.000,00,49 \%$ doaram valores até $\$ 499.000,00$ e 38\% realizaram doações de até $\$ 5.000,00{ }^{13}$

Outra observação importante é o grande aumento de pessoas que passam a contribuir a partir do início das construções do templo em 1913. Neste ano, a partir dos dados analisados, pode-se perceber que foram tomadas algumas iniciativas que influenciam diretamente tal característica. Fixou-se uma taxa única e igualitária a todos, e muitas pessoas que não haviam contribuído nos anos anteriores pagaram os valores 'atrasados'. Se imagina que houve uma espécie de campanha entre os

12 Valor mínimo estipulado para doação neste ano, de $\$ 4.000,00$.

13 Valor mínimo estipulado para o ano. 
moradores locais, buscando integrá-los ao objetivo de término da construção do templo, fazendo assim com que todos se envolvessem e passassem a contribuir.

Gráfico 3 - Número de doadores

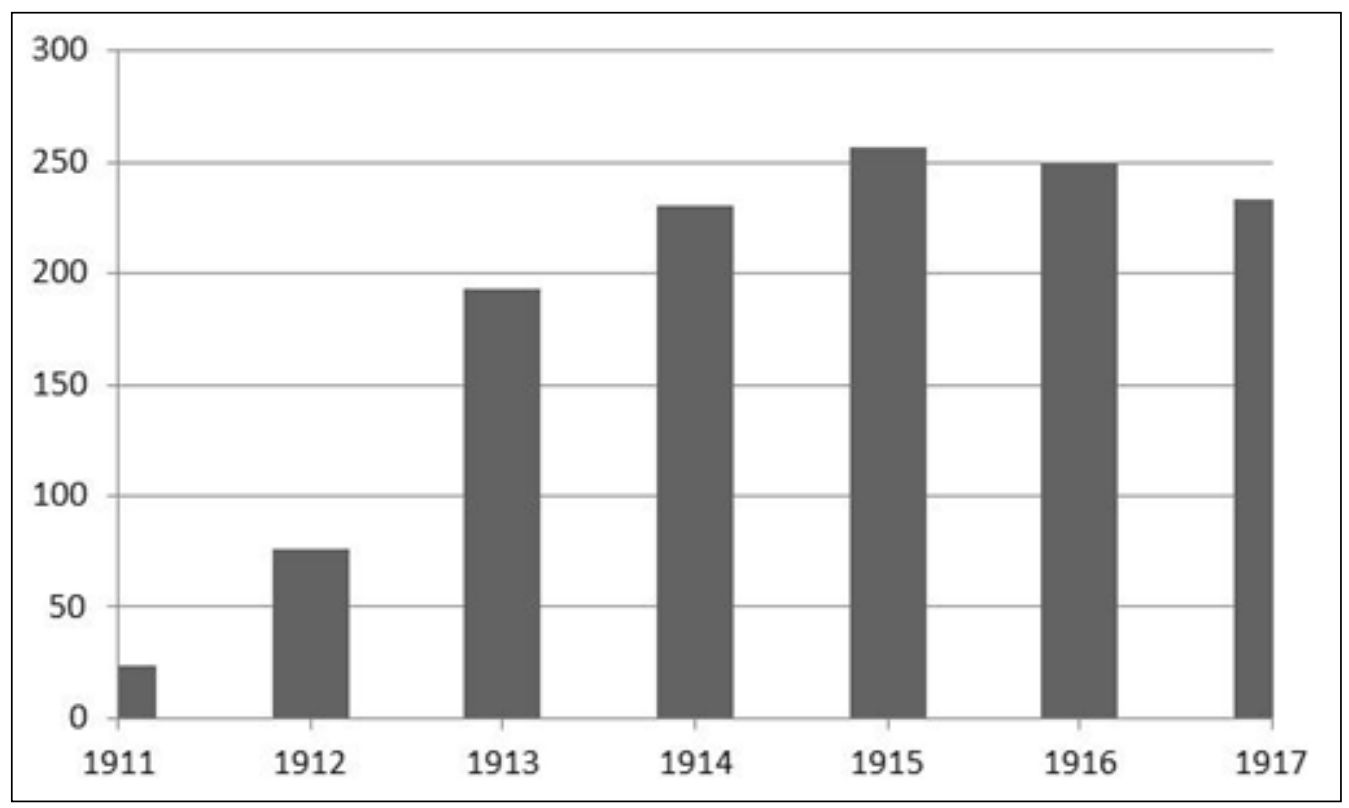

Fonte: Livro Caixa - Acervo Paróquia São Francisco Xavier (2015).

É importante ressaltar que as contribuições da comunidade não ocorreram somente através de doações em dinheiro. Muitos dos homens da comunidade participaram da construção do templo, através de mão-de-obra voluntária. Necessitando assim de uma reorganização familiar e comunitária para permitir a disponibilidade de tempo destas pessoas para o auxílio na obra, visto que a grande maioria caracterizava-se por trabalhadores da pequena agricultura familiar de subsistência e eram essenciais para o sustento dos núcleos familiares da comunidade.

Além disso, observou-se que, neste contexto, as mulheres são apresentadas apenas como personagens secundárias nos registros analisados. No ano de 1911, não consta nenhum registro de pagamento em nome de mulheres. Estes aparecem somente no ano seguinte, quando os nomes apareciam sempre após a intitulação de "viúva", muitas vezes o acompanhamento é somente o nome do marido, como por exemplo "Witwe Wilhelm Weber". ${ }^{14}$ No ano de $1915^{15}$, dos 257 doadores apenas 12 eram mulheres. Destas 12, três são identificadas como exemplificado anteriormente, oito são identificadas pelo seu próprio nome e pelo nome do seu marido, ou seja,

14 Escrito em alemão, pode ser traduzido como Viúva de Guilherme Weber.

15 Ano em que há o maior número de doadores. 
somente uma mulher é citada apenas pelo seu nome, sem um acompanhamento masculino. Revelam-se aí elementos da organização patriarcal desta sociedade.

Tabela 1 - Total de doadores por ano e a presença feminina nos registros

\begin{tabular}{ccc}
\hline Ano & Total de doadores & Total de mulheres \\
\hline 1911 & 24 & - \\
1912 & 76 & 2 \\
1913 & 193 & 8 \\
1914 & 230 & 12 \\
1915 & 257 & 12 \\
1916 & 249 & 12 \\
1917 & 233 & 17 \\
\hline
\end{tabular}

Fonte: Livro Caixa - Acervo Paróquia São Francisco Xavier (2015).

No conhecido livro "Cem anos de Germanidade no Rio Grande do Sul: 1824 - 1924", escrito pelo padre Theodor Amstad originalmente em alemão, e traduzido por Arthur Blasio Rambo, há uma imagem da referida igreja católica de Santa Clara, porém sem nenhuma referência escrita em relação à mesma. Para o autor, a evolução das igrejas católicas no estado é resultado da influência e da organização dos alemães e principalmente de sua fervorosa religiosidade. Nas regiões de colonização alemã "[...] existiam em 1920 nada menos do que 200 capelas ao lado das 25 igrejas paroquiais. A maioria dessas capelas e igrejas são construções sólidas de alvenaria. Somente Deus sabe quanto suor e quantos esforços em mutirões e quantas doações voluntárias em dinheiro, escondem essas construções de igrejas" (2005, p. 517). Percebe-se assim que as comunidades católicas, organizadas em regiões de imigração, apresentam algumas características que permitiram o grande envolvimento dos moradores nos projetos coletivos. Nesse sentido, a mobilização ocorrida em Santa Clara para a construção da Igreja Matriz São Francisco Xavier, precisa ser entendida a partir de um processo que congrega elementos de uma identidade religiosa capaz de provocar o engajamento da população.

\section{CONSIDERAÇÓES FINAIS}

A partir dos dados analisados, torna-se claro o envolvimento da Comunidade Católica de Santa Clara em prol da construção da Igreja Matriz São Francisco Xavier. Este envolvimento não ocorreu somente através de doações financeiras, mas também através de mão-de-obra voluntária de parte dos homens da comunidade. Para que estes tivessem tal disponibilidade, houve a necessidade de uma reorganização comunitária objetivando o sustento destas famílias, visto que em grande maioria eram formadas por pequenos agricultores, que mantinham suas famílias através do trabalho em suas propriedades. 
Chama a atenção ainda as grandes diferenças nos valores das doações registradas a cada ano. A partir da análise de tal dado, pode-se concluir que, após 50 anos do início da colonização, já havia uma organização comunitária bem estruturada, bem como havia diferenças sociais entre tal população, que possibilitaram grandes valores doados de algumas partes, e a necessidade de parcelamento do valor mínimo anual para outros moradores.

Em relação à população da comunidade, a partir da análise dos dados encontrados, pode-se afirmar que neste período havia em torno de 250 famílias católicas em Santa Clara. A Igreja Matriz São Francisco Xavier tornou-se desde então uma importante referência e um patrimônio da comunidade de Santa Clara do Sul. Ao visitar a cidade é possível que se compreenda que todo o centro surgiu no entorno do templo, sendo o mesmo até a atualidade justamente o marco referencial para localização no município. A religiosidade, como fator de congregação comunitária, permitiu aos moradores uma configuração social que os identifica ainda hoje.

\section{REFERÊNCIAS}

LANDO, Aldair Marli; BARROS, Eliane Cruxen. A colonização alemã no Rio Grande do Sul: uma interpretação sociológica. Porto Alegre: Movimento/IEL, 1976.

OLIVEIRA, Ryan de Sousa. Colonização alemã e poder: A cidadania brasileira em construção e discussão (Rio Grande do Sul, 1863-1889). 2008. 192 f. Dissertação (Mestrado em História) - Universidade de Brasília, Brasília, 2008.

RAMBO, Arthur Blásio. Cem anos de germanidade no Rio Grande do Sul: 18241924. São Leopoldo: Unisinos, 2005.

ROCHE, Jean. A Colonização Alemã e o Rio Grande do Sul. (vol. 1 e 2). Porto Alegre: Editora Globo, 1969.

SCHIERHOLT, José Alfredo. Lajeado I: povoamento, colonização e história política. Lajeado: Prefeitura Municipal, 1992.

SCHORR, Ana Paula; FALEIRO, Silvana Rossetti. A revolução federalista em Santa Clara do Sul: a versão dos descendentes dos combatentes. 2007. 47 f. Monografia (Licenciatura em História) - Curso de História, Centro Universitário Univates, Lajeado, RS, 2007.

TRÄSEL, Alberto. Álbum Jubilar de Santa Clara do Sul (100 anos de colonização: 1869 - 1969, e 40 anos de paróquia: 1929 - 1969), Impresso. Santa Clara do Sul, 1969.

COMO funciona o conversor de moedas. O Estadão. 09 dez. 2011. Disponível em: $<$ http://acervo.estadao.com.br/noticias/acervo,como-funciona-o-conversor-devalores,581,0.htm>. Acesso em 28 nov. 2015

SÍNTESE dos padrões monetários brasileiros. Banco Central do Brasil. Brasília, maio 2007. Disponível em: <http://www.bcb.gov.br/htms/museu-espacos/S\%C3\%ADnteseP adroesMonetariosBrasileiros.pdf>. Acesso em 28 nov. 2015. 